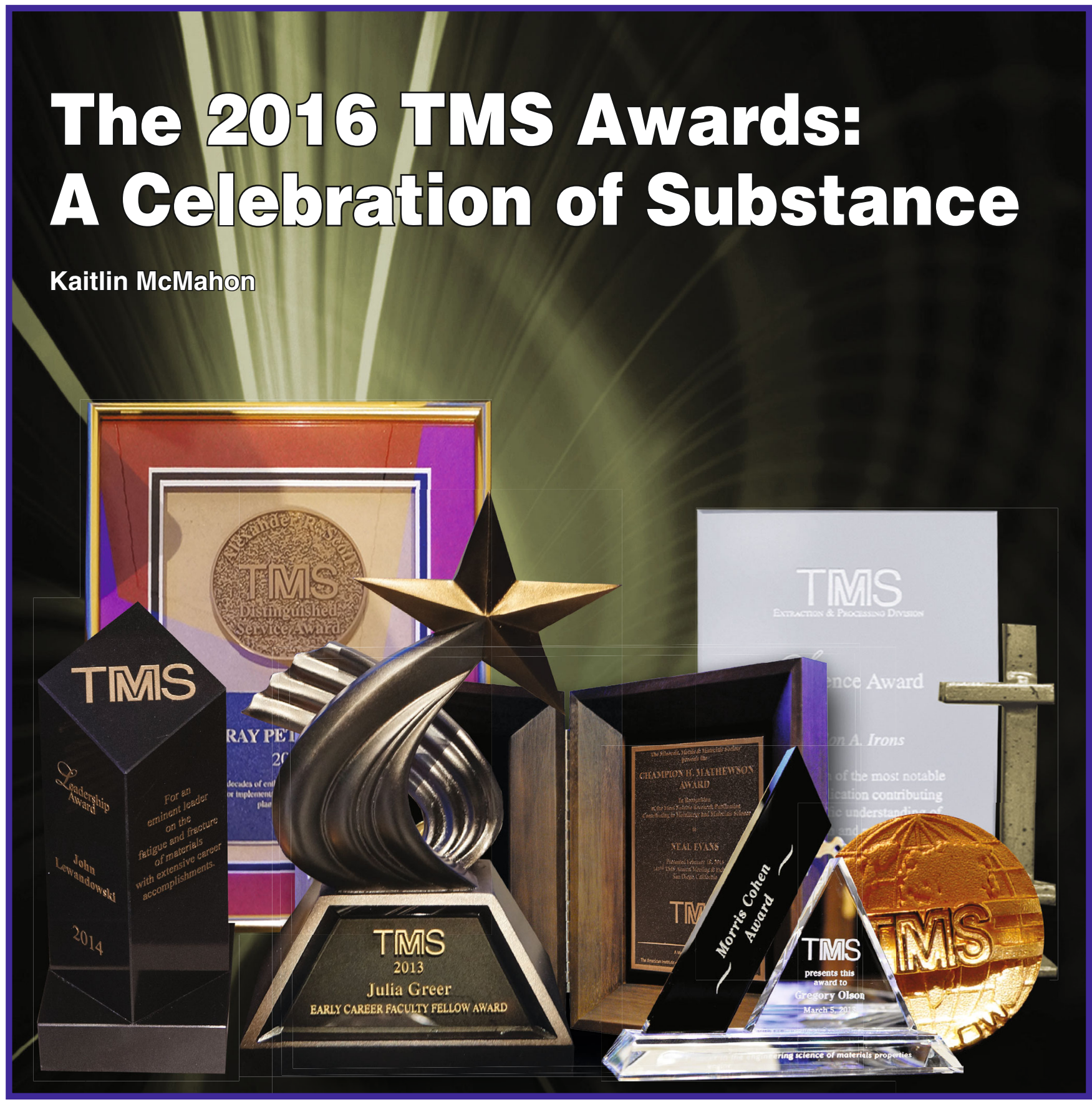

Each of the awards on the following pages recognizes an individual or team for diligence, dedication to, and excellence in a specific aspect of the TMS community. But they also celebrate science and engineering. The drive to advance the minerals, metals, and materials field is what keeps TMS members involved in the society, engaged in their work, and cognizant of the future. Receiving a prestigious TMS award is not only a professional milestone and validation of the awardees' efforts. It is also an inspiration for colleagues, friends, and students to see how great scientists and engineers continuously strive to move their professions into the future.

Many of these honorees will receive their awards at the
TMS 2016 Annual Meeting \& Exhibition, February 14-18 in Nashville, Tennessee. Members will have a chance to celebrate each other - to congratulate their colleagues and friends in person at meetings, technical sessions, and other events throughout the week or at the TMS-AIME Awards Ceremony on Tuesday, February 16.

Nominations for the majority of the 2017 TMS awards will be accepted until April 1, 2016. To nominate a colleague, visit the TMS Honors and Awards website at awards.tms.org for more details, including award criteria, applications, and instructions for submitting a nomination. For additional information, contact Deborah Hixon, TMS Awards and Recognition Specialist, at hixon@tms.org. 


\section{SOCIETY AWARDS}

\section{TMS FELLOWS}

The class of Fellow is TMS's highest honor. To be inducted, a candidate must be recognized as a leading authority and contributor to the practice of metallurgy, materials science, and technology, with strong consideration given for outstanding service to the Society.

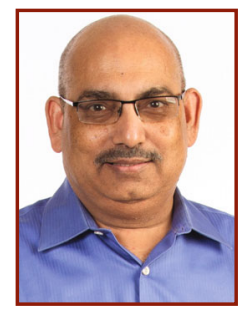

\section{Brajendra Mishra \\ Professor, Worcester Polytechnic Institute}

Citation: For his contributions to materials processing, extractive metallurgy, and his leadership in resource recovery and recycling.

"TMS Fellow is the most prestigious recognition I can imagine for any person's contributions to the materials engineering profession. Achieving it gives me a sense of fulfilment and satisfaction," said Mishra. "It is most gratifying when peers appreciate the value of one's work. I have reached out to TMS for most of my professional needs and the society has supported me over the past three decades. TMS membership has allowed me to hone both my technical and leadership skills."

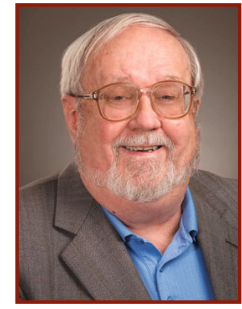

\section{G. Robert Odette}

Professor, University of California, Santa Barbara

Citation: For sustained contributions to irradiation effects in materials, leading to improved regulatory guidelines for nuclear reactor safety and development of advanced materials for fusion energy.

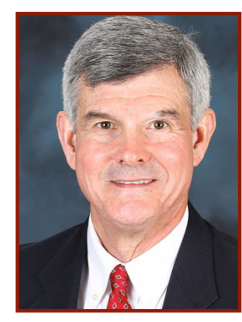

\section{George Pharr}

Professor, University of Tennessee

Citation: For developing

nanoindentation into a materials characterization tool that helped power the nanotechnology revolution and has been instrumental in the development of new materials.

"TMS has been an important professional partner for my entire working life. The annual meetings and technical publications have helped to shape and hone my technical skills, and the new friends and colleagues I have met at TMS events have been integral to my professional growth and development," Pharr said. "I am greatly honored to be chosen as a Fellow of the society and look forward to many more years of active membership and interaction."

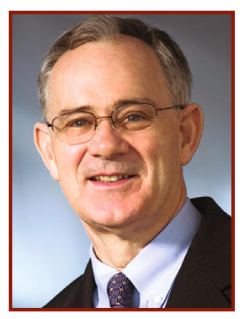

Ian Robertson

Professor, University of Wisconsin

Citation: In recognition for pioneering investigations on fundamental aspects of deformation and fracture of metal, particularly involving hydrogen effects, precipitates, and radiation damage. "I am deeply honored to receive this recognition from the materials community and, at the same time, humbled to join the list of TMS Fellows, all of whom are recognized leaders of the field. The TMS annual meeting remains an important forum for me to learn about the latest developments in the field and to stay connected with friends and colleagues," said Robertson.

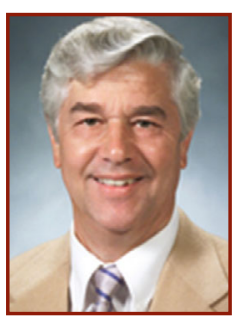

\section{James Smialek}

\section{Senior Research Scientist, NASA}

Citation: For significant contributions toward understanding and improving the high temperature corrosion of aerospace materials, including superalloys, intermetallics, ceramics, and coatings. "I am very grateful to TMS for this lifetime honor. My membership began 40 years ago and my first publications were in Metallurgical and Materials Transactions. Metallurgical research has been my avocation ever since - and TMS has offered premier opportunities for connecting with the materials community," Smialek commented. "On a personal level, it is especially gratifying to be included with such accomplished friends and mentors."

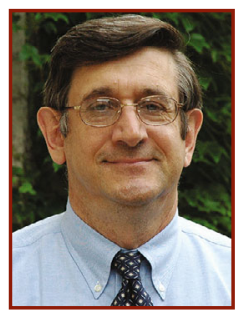

\section{Bruce Wessels} Professor, Northwestern University Citation: For seminal contributions to vapor phase epitaxy of phosphide, nitride, and oxide thin-films and heterostructures for electronic and optoelectronic applications, and the role of defects in determining their electronic and optical properties; additionally, for providing outstanding service to TMS.

"I have been active in TMS for most of my professional life. TMS membership has enabled me to partake in a number of activities including programming and leadership," said Wessels. "I had the honor of serving as the society's president during a period when TMS was undergoing significant changes, including the formation of the TMS Foundation. I am deeply appreciative of being named a Fellow of TMS by my colleagues." 


\section{SOCIETY AWARDS}

\section{BRIMACOMBE MEDALISTS}

This mid-career award recognizes individuals with: sustained excellence and achievement in business, technology, education, public policy or science related to minerals, metals, or materials science and engineering, and a record of continuing service to the profession.

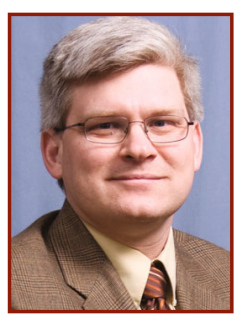

\section{David Bahr}

Head and Professor, Purdue University Citation: For outstanding contributions to understanding deformation and fracture at small scales, commitment to education, and continuing service to TMS and materials communities. "I'm honored to receive this award. As a TMS member since my undergraduate days, the society has been the place for me to present research, network with colleagues, listen to and find new ideas, and bring students to introduce them to the breadth of the field," said Bahr. "I appreciate this recognition, as TMS has been my professional home, the organization where I can couple scientific results with educational development and public outreach."

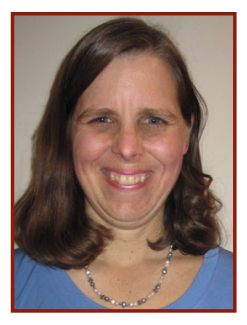

\section{Carelyn Campbell}

Leader, Thermodynamics and Kinetics Group, National Institute of Standards and Technology

Citation: For notable contributions in the assessment of diffusion data for multicomponent systems and their application to materials design and process improvement.

"I am honored to be recognized as a 2016 Brimacombe Medalist. I joined TMS as an undergraduate at Northwestern University in 1988 and have been a member ever since," Campbell said. "I am grateful for the many opportunities and all the mentors, colleagues, and friends TMS has provided me. I hope that I can continue the Brimacombe commitment to excellence in metallurgy and knowledge transfer to industry and can give back to TMS as much as it has given me."

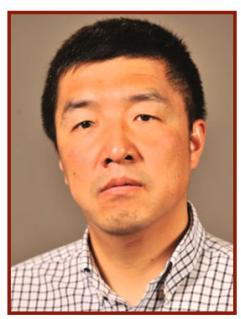

\section{Xingbo Liu} Professor and Associate Chair for Research, West Virginia University Citation: For significant contributions on the research and development of high temperature materials and coatings for energy applications, and for extensive service to TMS.

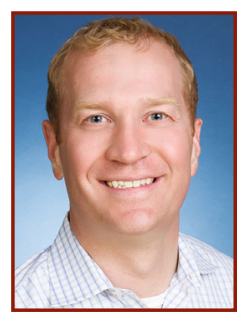

\section{James Yurko}

Citation: For sustained excellence and achievement in technology and entrepreneurship for casting and extraction of reactive metals. "Brimacombe was a towering figure in metals processing, and it is a privilege to receive an award named after him," said Yurko. "Active TMS membership has aided in the development of leadership skills critical to my career, and I've made a lot of great friends in the organization along the way. I encourage all young members to become active and participate in order to reap the benefits of this great professional society."

\section{APPLICATION TO PRACTICE AWARD}

This award recognizes an individual who has demonstrated outstanding achievement in transferring research results or findings into commercial production and practical use.

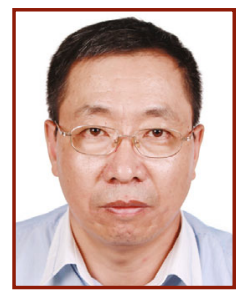

Guanghui Lang

Board Chair, Sunstone Development

Co. Ltd.

Citation: For innovative and environmentally friendly production of carbon anode from green petroleum coke, and development of waste heat recovery to generate electricity. "We've emphasized green technologies, maximizing the use of recycled materials and saving energy, reducing costs, and reducing pollutants for many years. The TMS Application to Practice Award is a special recognition for our achievements. With TMS's support, we hope to bring our technologies to the whole industry," Lang said.

\section{BRUCE CHALMERS AWARD}

Honors outstanding contributions to the science and/or technology of materials processing by an individual.

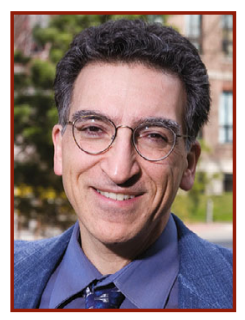

\section{Michael Aziz} Professor, Harvard University Citation: For basic theoretical and experimental contributions to the understanding of solute trapping, laser processing, and ion beam modification of surfaces.

"This award is special to me because of the high esteem in which I hold Chalmers as a pioneer of solidification," Aziz noted. "The first literature citation of my first publication is a paper by Biloni and Chalmers, where they made a conjecture about the kinetics that my work subsequently proved to be correct. As he had retired before I came to Harvard, I met him only once, but pointed this out to him, and he was pleased to hear the story." 


\section{SOCIETY AWARDS}

\section{MORRIS COHEN AWARD}

This award recognizes an individual who has made outstanding contributions to the science and/or technology of materials properties.

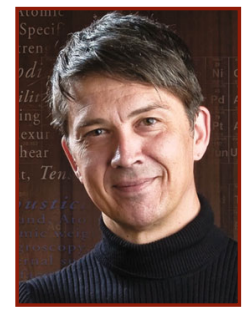

\section{Gerbrand Ceder}

Chancellor's Professor of Materials Science and Engineering, University of California, Berkeley

Citation: For pioneering and leading the development of computer aided materials discovery and design via quantum mechanical calculations of materials properties. "It is wonderful to be recognized with an award in the name of Morris Cohen," said Ceder. "Cohen transformed metallurgy by bringing fundamental science to it, and I am immensely proud to continue that tradition."

\section{EDUCATOR AWARD}

This award recognizes an individual who has made outstanding contributions to education in metallurgical engineering and/or materials science and engineering.

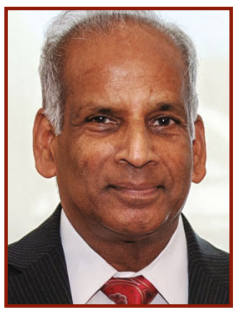

\section{Challapalli Suryanarayana} Professor, University of Central Florida Citation: For his over four decades of teaching to a large number of students, writing of popular textbooks, and his research contributions to nonequilibrium processing of materials. "I feel privileged and honored to receive this highly prestigious award," said Suryanarayana. "I am also grateful to many of my current and former students for giving me an opportunity to share the excitement of working in the continuously evolving field of materials science and engineering."

\section{WILLIAM HUME-ROTHERY AWARD}

This award recognizes exceptional scholarly contributions to the science of alloys.

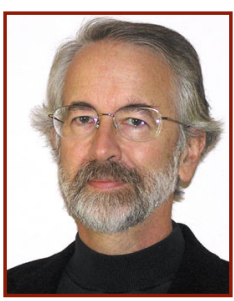

\section{Brent Fultz \\ Professor, California Institute of Technology}

Citation: For leadership in establishing the importance of vibrational entropy to the phase stability of alloys and for transformational advances in measurement techniques.

"I have deep respect for the previous recipients of the Hume-Rothery Award, so it will be an honor to receive this award at the TMS annual meeting," Fultz said. "I am a regular attendee of these meetings where I never fail to learn something from my colleagues."

\section{LEADERSHIP AWARD}

This award recognizes an individual who has demonstrated outstanding leadership in the national and international materials community.

\section{Enrique Lavernia}

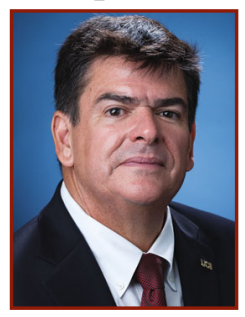

Dean and Distinguished Professor, University of California, Irvine Citation: For outstanding leadership in processing, properties, and fundamentals of advanced material as well as education.

"I joined TMS in my first year of graduate school in 1982. Since then, TMS has consistently provided me with opportunities for professional growth and engagement," Lavernia said. "I have benefitted from the technical conferences, and even today, TMS conferences energize my thinking about important research problems."

\section{ALEXANDER SCOTT DISTINGUISHED SERVICE AWARD}

This award recognizes a member's outstanding contributions to TMS and is typically presented for 10 or more years of TMS service in one or more of the following areas: membership development, student chapters, education and professional affairs, or other society-level activities.

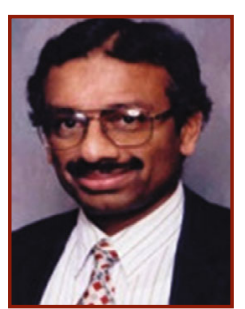

Tirumalai "Sri" Srivatsan Professor, University of Akron Citation: Far and beyond outstanding service stemming from a contagious amount of dedication inlaid with dependable diligence and shadowed with dynamism at initiating by way of proposing, all intrinsic intricacies related to organizing, from conception to completion, followed by conducting both symposia and conferences in the domain spanning the many marvels of materials. Said Srivatsan, "Membership in TMS has enabled me to find like-minded individuals who are willing to dedicate their energy and enthusiasm toward the efficient execution of symposia." 


\section{SOCIETY AWARDS}

\section{CYRIL STANLEY SMITH AWARD}

Outstanding contributions to the science and/or technology of materials structure is the focus of this award.

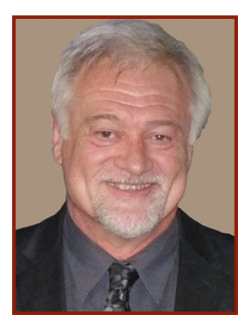

\section{Carlos Tomé}

Technical Staff Member, Los Alamos

National Laboratory

Citation: For pioneering the

development of physically-based,

multi-scale, microstructural models

that capture the mechanical response of

highly textured, anisotropic materials.
"I am honored by the recognition bestowed on my by TMS. I would like to acknowledge that the body of work that this award recognizes is a paradigm of how scientific research works at its best," said Tomé. He continued: "It builds upon previously developed foundations; it results from teamwork and continuity; and its character reflects contributions from and collaborations with a variety of first-class researchers."

\section{AIME AWARDS}

\section{AIME HONORARY MEMBERSHIP}

Conferred on an individual for outstanding service to or distinguished scientific or engineering achievement in the fields embracing the activities of the American Institute of Mining, Metallurgical, and Petroleum Engineers (AIME) and its member societies.

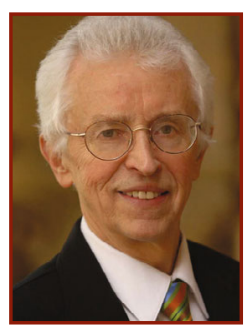
Siegfried Hecker
Director, Los Alamos National
Laboratory
Citation: For his seminal contributions to plutonium science, nuclear weapons policy, international security, nuclear threat reduction, and global future of nuclear energy.

\section{AIME JAMES DOUGLAS GOLD MEDAL}

Honors distinguished achievement in nonferrous metallurgy, including both the benefication of ores and the alloying and utilization of nonferrous metals. This award is administered through TMS's Extraction \& Processing Division (EPD) and the Society for Mining, Metallurgy \& Exploration's Minerals \& Metallurgical Processing Division (MPD).

\section{Daniel Kappes}

\section{President, Kappes, Cassiday \& Associates}

Citation: For his numerous contributions to the mining industry and for his generous support of higher education.

\section{AIME ROBERT LANSING HARDY AWARD}

For more than half a century, this award has recognized professionals under the age of 35 in the broad fields of metallurgy and materials science for exceptional promise of a successful career.

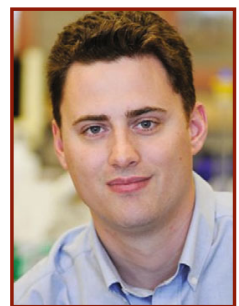

Edouard Asselin Professor, University of British Columbia

Citation: For early and important contributions to teaching, research, and service in extractive metallurgy. "I am honored to receive this award and I am most grateful to TMS and my nominators," said Asselin. "As a young researcher I have benefitted from excellent mentorship, some of it through TMS. These experiences have profoundly shaped my career, and this award would not have been possible without it."

\section{AIME CHAMPION H. MATTHEWSON AWARD}

Awarded to the author(s) of a paper, or series of closely related papers, representing the most notable contribution to metallurgical science during the period under review.

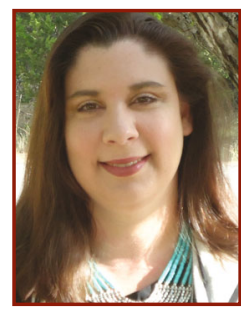

Laura Bartlett

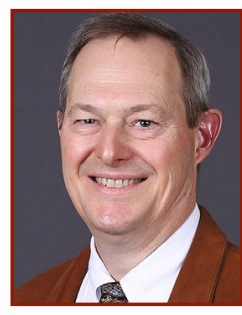

David Van Aken

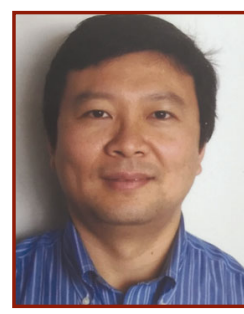

Kai Song
Laura Bartlett, Assistant Professor, Texas State

University; David Van Aken, Curators' Teaching Professor, Missouri University of Science and Technology (MUST); Julia Medvedeva, Associate Professor, MUST; Dieter Isheim, Research Assistant Professor, Northwestern University; Nadezhda Medvedeva, Leading Researcher, Institute of Solid State Chemistry; Kai Song, Senior Applications Engineer, FEI Company

Paper: "An Atom Probe Study of Kappa Carbide Precipitation and the Effect of Silicon Addition," Metallurgical and Materials Transactions A, Vol. 45, May 2014.

"I am greatly humbled and honored to be receiving this 


\section{AIME AWARDS}

award. Of course none of this would have been possible without the outstanding work of my co-authors," said Bartlett. Van Aken continued: "TMS was the gateway for my academic career and I will always be grateful to TMS for providing me with that opportunity." Song commented: "It is a great honor that our work has been recognized as being a notable contribution."

\section{AIME ROSSITER W. RAYMOND MEMORIAL AWARD}

This award recognizes the best paper published by an AIME society in a given period where the lead author is a member under 35 years of age.

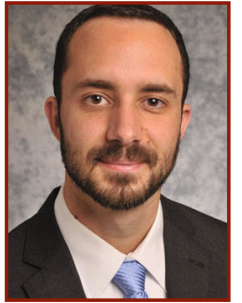

William Joost U.S. Department of Energy

Paper: "Reducing Vehicle Weight and Improving U.S. Energy Efficiency Using Integrated Computational Materials Engineering," JOM, Vol. 64, Sept. 2012. "Communicating among our technical community via publication is an essential catalyst for advancing our field," Joost commented.

"Membership in TMS affords tremendous opportunities: to learn from and interact with the best researchers, to network and collaborate with colleagues and friends, and to participate in the journals and committees that move materials science and engineering forward."

\section{ACTA MATERIALIA AWARDS}

\section{ACTA MATERIALIA GOLD MEDAL AWARD}

Awarded to a proven leader in materials science and

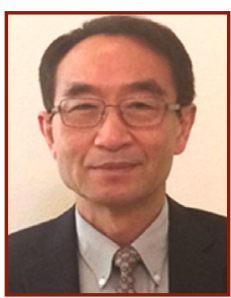

engineering whose research has significantly impacted the development of the discipline.

\section{Sungho Jin Professor Emeritus, University of California, San Diego}

\section{ACTA MATERIALIA HOLLOMON MATERIALS \& SOCIETY AWARD}

This recognition honors an individual who promotes

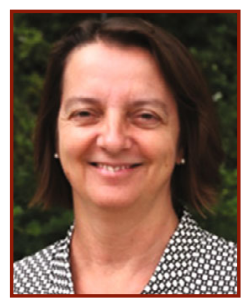
understanding of the relationship and interactions between materials technology and societal interest or needs.

Julie Schoenung

Professor, University of California, Davis

\section{DIVISION AWARDS}

\section{EXTRACTION \& PROCESSING DIVISION (EPD) DISTINGUISHED LECTURE AWARD}

An outstanding scientific leader in the field of nonferrous extraction and processing metallurgy is invited to present a comprehensive lecture at the TMS annual meeting to recognize his or her contributions.

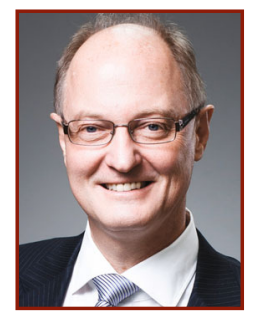

$$
\begin{aligned}
& \text { Markus Reuter } \\
& \text { Director and Professor, Helmholtz- } \\
& \text { Zentrum Dresden-Rossendorf, Helmholtz } \\
& \text { Institute Freiberg for Resource } \\
& \text { Technology } \\
& \text { Lecture: "Digitalizing the Circular } \\
& \text { Economy-System-Integrated-Material- } \\
& \text { Production" }
\end{aligned}
$$

"A copper smelter was the first plant I ever visited when I was a boy of five years. The color of copper and its minerals fascinated me," Reuter recalled. "Ever since then, metals formed a part of my life. It is a wonderful journey of discovery and doing, trying to contribute to a sustainable world, with TMS being a special part of my journey."

\section{EPD PYROMETALLURGY BEST PAPER AWARD}

Recognizes individual excellence of a paper published in the proceedings volume of the EPD pyrometallurgy symposium from the previous year.

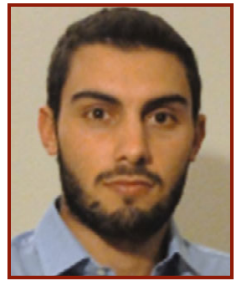

Nikolaos Tzouganatos

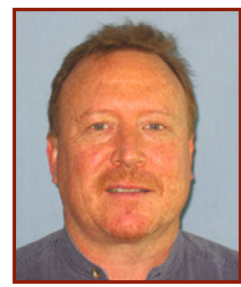

Mark Dell'Amico

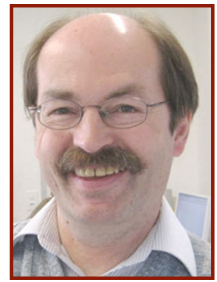

Christian Wieckert
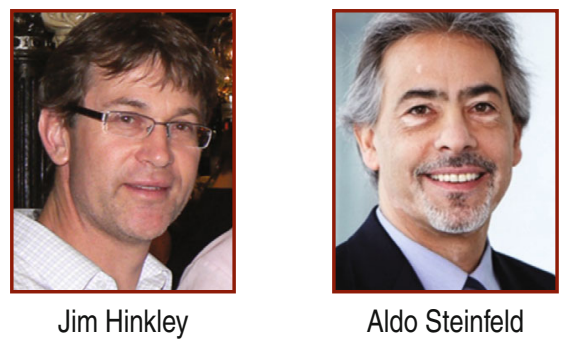

Aldo Steinfeld

Nikolaos Tzouganatos, Paul Scherrer Institute; Mark Dell'Amico, Consultant; Christian Wieckert, Project Leader, Paul Scherrer Institute; Jim Hinkley, Senior Research Scientist, CSIRO Energy Technology; Aldo Steinfeld, Professor, ETH Zurich 


\section{DIVISION AWARDS}

Paper: "On the Development of a Zinc Vapor Condensation Process for the Solar Carbothermal Reduction of Zinc Oxide," JOM, Vol. 67, May 2015.

"I would like to take this moment and thank TMS for this very honorable recognition of our work," said Tzouganatos. Dell'Amico continued: "TMS is a highly respected society for professionals. The award is a great recognition."

\section{EPD SCIENCE AWARD}

This award recognizes a paper, or series of closely related papers, with at least one common author, which represent a notable contribution to the scientific understanding of extraction and processing metallurgy, with an emphasis on nonferrous metals.

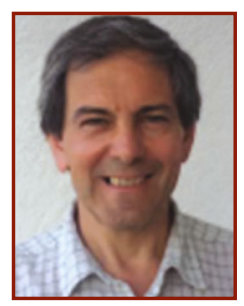

Paolo Scardi

Mahmoud Abdellatief, Materials Science-Beamline Scientist, SESAME; Andrea Lausi, Head MCX Beamline, Elettra-Sincotrone Trieste; Jasper R. Plaisier, Researcher MCX Beamline, Professor, University of Toronto Paper: "Influence of Lattice Defects Elettra-Sincotrone Trieste; Paolo Scardi; on the Grain Growth Kinetics of Nanocrystalline Fluorite," Metallurgical and Materials Transactions A, Vol. 45, Jan. 2014.

"TMS has been a reference over the past year for qualified sessions and opportunity to meet colleagues from many different countries and research fields," Scardi noted. "It is a real honor that our work has drawn attention and is acknowledged as an important contribution to the scientific literature."

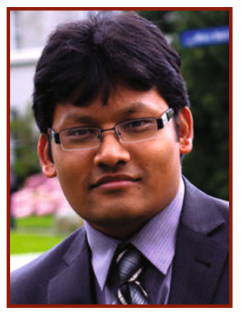

Subrata Roy

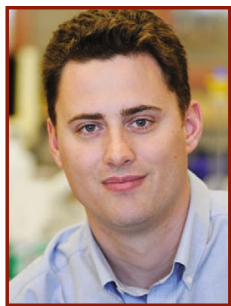

Edouard Asselin
Subrata Roy, Metallurgist, New Gold; Hamidreza Zebardast, Corrosion Engineer, Acuren; Edouard Asselin, Professor, University of British Columbia Paper: "On the
Development of Thermo-Kinetic Eh-pH Diagrams," Metallurgical and Materials Transactions B, Vol. 43, Dec. 2012.

"While I was working on this project, I felt passionate about the metal extraction research and decided to pursue my career in this field. It's a great honor to be recognized by TMS," said Roy. "This recognition will encourage me to continue my industrial career in extraction and mineral processing field."

\section{EPD TECHNOLOGY AWARD}

Conferred on a paper that represents a notable contribution to the advancement of the technology of extraction and processing metallurgy, with emphasis on nonferrous metals.

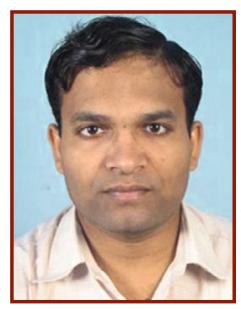

Ashutosh Sharma

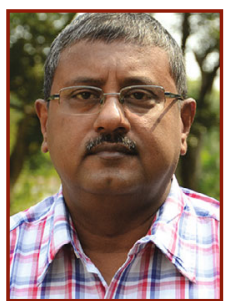

Siddhartha Das

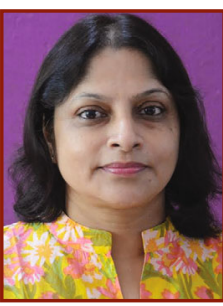

Karabi Das
Ashutosh Sharma, Institute Chair Professor and C.V. Seshadri Chair Professor, Indian Institute of Technology (IIT), Kharagpur; Sumit Bhattacharya, Student, Northwestern University; Siddhartha Das, Professor, IIT Kharagpur; Karabi Das, Professor, IIT Kharagpur Paper: "A Study on the Effect of Pulse Electrodeposition Parameters on the Morphology of Pure Tin Coatings," Metallurgical and Materials Transactions A, Vol. 45, Sept. 2014.

"This award truly inspires me to focus more on basic materials research and development," Sharma said. "This is indeed a great opportunity to get involved and contribute more to the materials research community and TMS is the perfect venue for this." S. Das agreed, saying, "It is a great honor to receive this award from TMS, one of the most prestigious materials societies in the world." K. Das likewise commented: "I am greatly humbled, honored, and excited to receive this award."

\section{FUNCTIONAL MATERIALS DIVISION (FMD) JOHN BARDEEN AWARD}

This award is presented to an individual who has made outstanding contributions to and is a leader in the field of electronic materials.

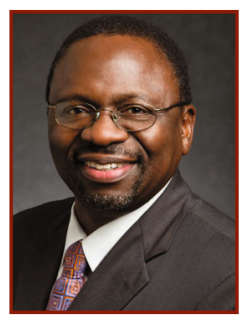

\section{Ilesanmi Adesida \\ Professor, University of Illinois at Urbana-Champaign \\ Citation: For sustained contributions to compound semiconductor materials processing and leadership in nanofabrication. \\ "It is a tremendous honor to win an} award named after John Bardeen. When I joined the faculty at the University of Illinois at Urbana-Champaign in 1987, I made it a point of duty to visit his office just to see him," Adesida recalled. "He was a gentle man but we all know that he was a giant; his work changed the world and the course of mankind. It is indeed a great honor to follow in the previous recipients' footsteps and I am proud to be a member of the TMS community." 


\section{DIVISION AWARDS}

\section{FMD DISTINGUISHED SCIENTIST/ENGINEER AWARD}

Honors research excellence in one or several areas related to electronic, magnetic, and photonic materials science; technology impact; broad, sustained commitment to teaching or mentoring; service to TMS and/or the profession; and impact upon government or policy-making bodies.

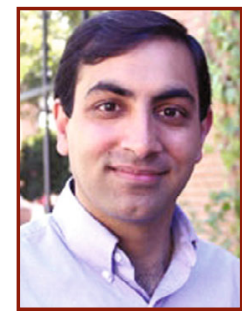

\section{Nikhilesh Chawla}

Professor, Arizona State University

Citation: For outstanding research, scholarship, and teaching in the field of solders, specifically in developing novel techniques for characterization and modeling the mechanical behavior of lead-free solders.

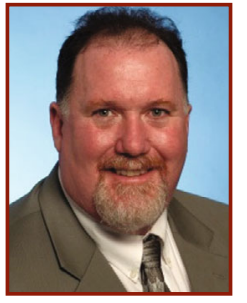

Vincent Harris

Distinguished Professor and W.L. Smith Chair Professor, Northeastern University

Citation: For his outstanding contribution to the understanding and application of magnetic ferrites and radio frequency microwave materials.

"It is my great honor to be recognized by TMS, the FMD, and my peers for this distinguished award. Membership in TMS has always been a source of great pride for me," said Harris. "Not only does the annual meeting provide a forum to broadly disseminate timely research advances, but it also provides a means to nurture professional relationships and establish lifelong friendships."

\section{LIGHT METALS DIVISION (LMD) LIGHT METALS AWARD}

Awarded to the author(s) of a paper presented in the preceding year in an LMD-sponsored session at the annual meeting, which notably exemplifies the solution of a practical problem.

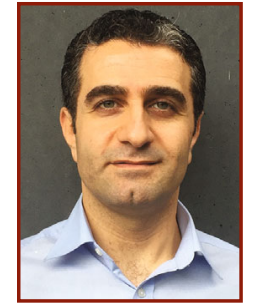

Fadi Abu-Farha

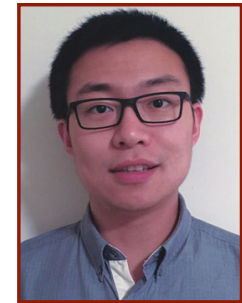

Nan Zhang
Fadi Abu-Farha, Assistant Professor, Clemson University; Nan Zhang, Student, Clemson University Paper: "Characterizing and Modeling the Deformation of
AA5182 for Hot Blank - Cold Die (HB-CD) Stamping," Light Metals 2015.

"It is a great honor to receive this award, especially for the first research paper I publish in my life," noted Zhang. Abu-
Farha said, "This award affirms the significance and quality of the research I have been working on over the past years. I joined TMS on my first year as a graduate student, and it has been such a fantastic journey; TMS has been educational and inspirational through the conferences and publications that offer great opportunities to learn and exchange ideas with the top talents from around the world." Note: This paper also earned the Aluminum Alloys Subject Award.

\section{LMD DISTINGUISHED SERVICE AWARD}

Award recipients are individuals whose continuous service to the LMD activities has facilitated TMS's capability to serve its light metals-oriented members and their supporting organizations.

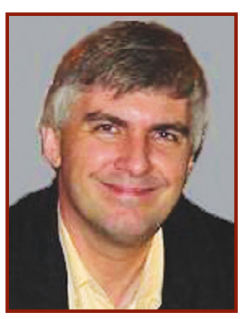

Stephen Lindsay Manager, Process Technology, Alcoa Inc.

Citation: For meeting and exceeding all of the award criteria: 30 years of membership to TMS, prime mover in organizing and advancing TMS programs, work and planning at all levels of the LMD, clarity and quality of work that inspires and assists future contributors to the society.

"The collaborative efforts, contacts, international acquaintances, and friendships that are behind this award mean a lot," Lindsay reflected. "I have said on occasion that in many cases you get out of something that which you put into it. Being a volunteer to TMS I have found that no matter how much you put in, it is generally far short of what you get back in return."

\section{LMD ENERGY BEST PAPER}

Recognizes excellence of a paper published in the preceding year's volume of the energy proceedings or in a TMS journal.

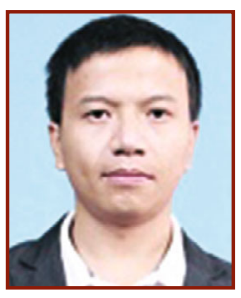

Lejun Zhao

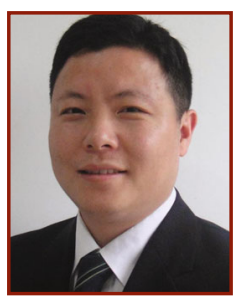

Wanlin Wang

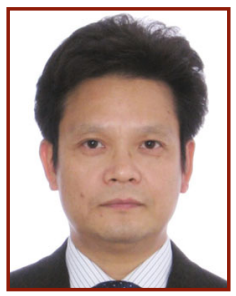

Kechao Zhou
Professional Division:

Lejun Zhou, Lecturer, Central South University; Wanlin Wang, Director, Central South University; Kechao Zhou, Central South University

Paper: "Effect of $\mathrm{Al}_{2} \mathrm{O}_{3}$ on the Crystallization of Mold Flux for Casting High Al Steel," Metallurgical and Materials Transactions E, Vol. 2, Jun. 2015. 


\section{DIVISION AWARDS}

Upon being awarded this honor, L. Zhou, Wang, and K. Zhou all commented: "It is our great honor to be chosen for this award. It means our work has been acknowledged by our international research family, which will further encourage us to work hard for our research and contribute to the future energy saving technology. We appreciate this award, and believe it will highlight the current advanced energy saving technology and expose it to a wide international community."

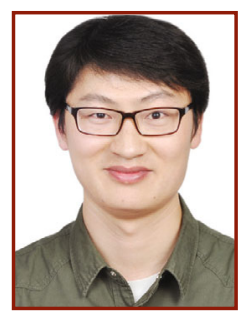

Yongqi Sun

Student Division: Yongqi Sun, Student, Peking University; Zuotai Zhang, Professor, Peking University

Paper: "Investigation of the Heat Recovery from High Temperature Slags," Energy Technology 2015.

"I am deeply honored to be chosen as the recipient of this award," said Sun. "Being able to talk with my friends, other students, professors, and members of TMS at the TMS annual meeting is always, for me, an enjoyable thing."

\section{LMD TECHNOLOGY AWARD}

This award honors an individual who has demonstrated outstanding long-term service to the light metals industry by consistently providing technical and/or operating knowledge that has enhanced the competitiveness of the industry.

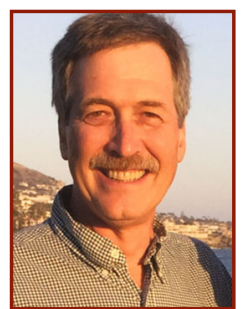

\section{Ray Peterson}

Technology Director, Real Alloy

Citation: For contributing to the

knowledge base of the light metals community in primary production, recycling, molten metal treatment, and energy management.

"I am honored to be recognized by my colleagues with the Light Metals Technology Award. The LMD of TMS has been my technical home for my entire career," said Peterson. "I've learned so much from the current and past members of this community. I hope to provide similar guidance and service to others by continuing to foster a strong sense of community and contributing to the body of knowledge."

\section{MATERIALS PROCESSING \& MANUFACTURING DIVISION (MPMD) DISTINGUISHED SERVICE AWARD}

An individual whose dedication and commitment to the MPMD have made a demonstrable difference to the objectives and capabilities of the division and TMS is honored with this award.

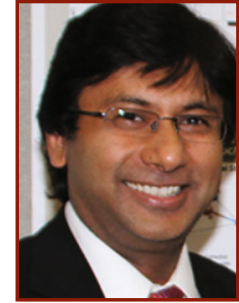

\section{Amit Misra}

Professor, University of Michigan

Citation: For his tireless commitment to service to TMS, the MPMD, and the Nanomechanical Material Behaviors Committee, and promotion of TMS as the home society for nanomechanics.

"I am proud to be a member of TMS and feel honored with this recognition for my service. I thank the MPMD Council and the Nanomechanical Materials Behavior Committee for the support and encouragement to continue as a volunteer for as long as I remain active in the materials science and engineering profession," Misra said.

\section{STRUCTURAL MATERIALS DIVISION (SMD) DISTINGUISHED SERVICE AWARD}

This award honors an individual whose dedication and commitment to the SMD has made a demonstrable difference to the objectives and capabilities of the division and TMS.

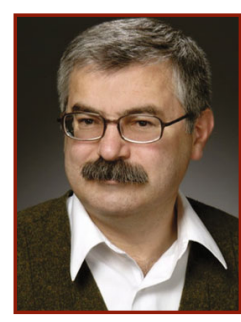

Raul Rebak

Corrosion and Materials Scientist, GE Global Research

Citation: For outstanding contribution to the permanency and good standing and of the Corrosion and Environmental Effects and the Nuclear Materials Committees of the SMD.

"I am honored and proud to be a member of TMS for 25 years, since I was a graduate student," said Rebak. "Being a member of TMS and involved in committee activities is extremely important because we can influence what subjects are addressed by the symposia at the annual meetings."

\section{SMD DISTINGUISHED SCIENTIST/ENGINEER AWARD}

Recognizes long-lasting contributions to the fundamental understanding of microstructure, properties, and performance of structural materials for industrial applications.

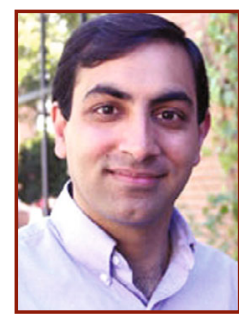

\section{Nikhilesh Chawla} Professor, Arizona State University Citation: For outstanding, sustained contributions to our understanding of structural materials in the areas of aluminum alloys and their composites, lead-free solders, and three-dimensional microstructure characterization. 


\section{LIGHT METALS SUBJECT AWARDS}

The following awards recognize individual excellence of papers presented at the previous year's TMS annual meeting in an LMD-sponsored session.

\section{Alumina \& Bauxite}

Peter-Hans ter Weer, Director, TWS Services \& Advice BV Paper: "Sustainability and Alumina Refinery Design," Light Metals 2015.

\section{Aluminum Reduction Technology}

Zhao ZhiBin, Student, Northeastern University (NEU); Yuqing Feng, Senior Research Scientist, CSIRO; Bingliang Gao, Professor, NEU; Zhao-wen Wang, Professor, $N E U$; Zhong-ning Shi, Professor, NEU; Xianwei Hu, Associate Professor, NEU

Paper: "Observation of Anodic Bubble Behaviors on Unslotted Anode and Slotted Anode in a Laboratory Scale Transparent Aluminium Electrolysis Cell," Light Metals 2015.

Electrode Technology for Aluminum Production Winifred Boenigk, Head of R\&D, Rütgers Basic Aromatics GmbH; Claudia Boltersdorf, Rütgers Basic Aromatics; Christopher Kuhnt, Project Manager, Rütgers Basic Aromatics; Jens Stiegert, Director of Sales, Rütgers Basic Aromatics; Les Edwards, Chief Technology Officer, Rain CII Carbon LLC; Marvin Lubin, Customer Tech Support Manager, Rain CII Carbon

Paper: "Pilot Anode Testing of Alternative Binder and CPC Raw Materials," Light Metals 2015.

\section{Recycling}

Bingyi Song, Student, Wenlong Jiang, Bin Yang, Baoqiang Xu, Qitong Yang, Shuai Xu, Dachun Liu, Kunming University of Science and Technology Paper: "Investigation on Recycling of $\mathrm{Ag}$ From $\mathrm{Pb}-\mathrm{Cu}-\mathrm{Ag}$ Alloy by Vacuum Distillation," Energy Technology 2015.

\section{Warren Peterson Award Cast Shop for Aluminum} Production

Robert Fritzsch, Student, Norwegian University of Science and Technology (NTNU); Mark Kennedy, Chief Technology Officer, Proval Partners SA; Shahin Akbarnejad, Ph.D. Fellow, Royal Institute of Technology; Ragnhild E. Aune, Professor, NTNU Paper: "Effect of Electromagnetic Fields on the Priming of High Grade Ceramic Foam Filters (CFF) with Liquid Aluminum," Light Metals 2015.

\section{LMD MAGNESIUM TECHNOLOGY AWARDS}

The following recognize individual excellence of papers published in the previous year's volume of Magnesium Technology on specific topics or presented during the TMS annual meeting at the Magnesium Technology Symposium.

\section{Best Paper - Application}

Piotr Korczak, Assistant, Institute of Non-Ferrous Metals (IMN); Bartlomiej Płonka, Head of the Light Metals Processing Plant, IMN; Dariusz Leśniak, Professor, AGH University of Science and Technology; Marek Nowak, Head of the Laboratory of Corrosion and Surface Engineering, IMN; Krzysztof Remsak, Engineering and Technical Specialist, IMN; Sonia Boczkal, Lecturer, IMN

Paper: "Studies on the Magnesium Alloys Cladding in the Plastic Formation Process (Die Forging and Extrusion) using as the Clad Layer Corrosion Resistant Aluminum Alloys," Magnesium Technology 2015.

\section{Best Paper - Fundamental Research}

Taisuke Sasaki, Researcher, National Institute for Materials Science (NIMS); Tilak Bhattacharjee, University of Kyoto; Byeong Chan Suh, NIMS; Taiki Nakata, Student, Nagaoka University of Technology; Shigeharu Kamado, Professor and Director for RCAMT, Nagaoka University of Technology; Nack Joon Kim, Professor, Pohang University of Science and Technology; Kazuhiro Hono, NIMS Fellow and Director of Magnetic Materials Center, NIMS

Paper: "Role of $\mathrm{Zr}$ in the Microstructure Evolution in $\mathrm{Mg}$ Zn-Zr Based Wrought Alloys," Magnesium Technology 2015.

\section{Student Paper}

Jishnu Bhattacharyya, Student, University of Virginia (UVA); Sean Agnew, Associate Professor, UVA; Peidong Wu, Professor, McMaster University; Wilburn Whittington, Research Associate, Mississippi State University (MS State); Haitham El Kadiri, Assistant Professor, MS State

Paper: "Crystal Plasticity Modeling of the Dynamic Behavior of Magnesium Alloy, WE43-T5, Plate," Magnesium Technology 2015.

\section{Best Poster}

Sivanesh Palanivel, Graduate Research Assistant, University of North Texas (UNT); Rajiv S. Mishra, Professor, UNT; Raymond Brennan, Materials Engineer, U.S. Army Research Laboratory $(A R L)$; Kyu C. Cho, Materials Engineer, $A R L$ Paper: "Analysis of Dislocation Mediated Precipitation in An Mg-Y-Nd Alloy" 